\title{
The effectiveness of virtual reality training in reducing the risk of falls among elderly people
}

This article was published in the following Dove Press journal:

Clinical Interventions in Aging

\author{
Magdalena Sylwia Kamińska' \\ Agnieszka Miller ${ }^{2}$ \\ Iwona Rotter ${ }^{3}$ \\ Aleksandra Szylińska ${ }^{3}$ \\ Elżbieta Grochans ${ }^{4}$ \\ 'Department of Primary Health \\ Care, Faculty of Health Sciences, \\ Pomeranian Medical University in \\ Szczecin, 7 I-2 I 0 Szczecin, Poland; \\ ${ }^{2}$ Holistic Agnieszka Miller, 66-450 \\ Bogdaniec, Poland; ${ }^{3}$ Department of \\ Medical Rehabilitation and Clinical \\ Physiotherapy, Faculty of Health \\ Sciences, Pomeranian Medical \\ University in Szczecin, 7 I-210 \\ Szczecin, Poland; ${ }^{4}$ Department of \\ Nursing, Faculty of Health Sciences, \\ Pomeranian Medical University in \\ Szczecin, 7I-2I0 Szczecin, Poland
}

Correspondence: Magdalena Sylwia

Kamińska

Department of Primary Health

Care, Faculty of Health Sciences,

Pomeranian Medical University

in Szczecin, 48 Żołnierska Street,

7I-210 Szczecin, Poland

Tel +489l 4800973

Email magdalena.kaminska@pum.edu.pl
Background: Virtual reality (VR) training using modern game consoles is an innovative rehabilitation method for fall-prone elderly people. The aim of this study was to assess the effectiveness of VR training using the "Xbox 360 Kinect" in people over 60 years of age.

Materials and methods: The study involved 23 people, including 19 women and 4 men (mean age $75.74 \pm 8.09$ years). The following functional tests were employed as research instruments: the 6-minute walking test (6MWT), the Dynamic Gait Index (DGI), the tandem stance test (TST), the tandem walk test (TWT), and the Beck Depression Inventory (BDI). A "spring hand dynamometer" was also used. The participants underwent 30-day VR training using an Xbox 360 Kinect. They trained 3 times a week, with each exercise lasting 30 minutes.

Results: The 6MWT $(P<0.001)$, the DGI $(P=0.008)$, the TST $(P<0.001)$, the TWT $(P=0.002)$, and the BDI $(P<0.001)$ outcomes were significantly improved. There were differences in the results for the strength of the "pressing muscles" in the right $(P=0.106)$ and left $(P=0.043)$ hands of the participants. Both participants under 80 years of age and those aged 80 years and over had visibly better results on the 6MWT $(P<0.001$ and $P=0.008$, respectively), the TST $(P<0.001$ and $P=0.008$, respectively), and the BDI ( $P=0.003$ and $P=0.012$, respectively).

Conclusion: Training based on VR increases the possibilities of motor training and can help reduce the risk of falls by improving the static and dynamic balance.

Keywords: virtual reality, Xbox 360 Kinect, elderly people

\section{Introduction}

The aging of societies is a global phenomenon. The lengthening of the average human lifespan and the consequent increase in the advanced-age population can be ascribed to general improvements in social and living conditions and to progress in rehabilitation and medical science. ${ }^{1}$

Falls are defined as unintentional events that result in a person coming to rest inadvertently on the ground, floor, or other lower level, without any specific physical forces coming into play. Falls are numbered among the so-called geriatric giants. They may result in the limitation of patients' independence and their long-term immobilization, which can predispose them to various complications and clinical pathologies. All these entail either a risk of hospitalization or longer and more costly hospital stays, leading in consequence to the lowering of patients' quality of life and their untimely death. Proneness to falls is underlain by numerous factors and is mostly observed in people over 65 years, since the efficiency of the balance control system substantially decreases with age..$^{2-4}$

Some of the factors predisposing elderly people to falls include sex and age, as well as a number of external (behavioral, environmental, and socioeconomic) and internal (health-related) factors. ${ }^{2}$ 
The fall risk factors associated with involutional changes involve a slowdown in nerve conduction velocity and the longer reaction time that results from this, motor coordination difficulties, impairment of superficial and deep sensation, impaired distance visual acuity, impairment of peripheral vision, impairment of hearing, worse spatial imagination, a decrease in the strength and tension of the lower limb muscles, degenerative changes in the ligament-tendon system, and changes in gait patterns (walking in shorter steps, not taking the feet off the ground, a slowdown and uncertainty in the cyclic and alternating movements of the limbs and torso, the lengthening of the double support phase, limited rotation of the knee and hip joint, increased physiological postural deflection, and postural bending with the center of gravity shifted forward)., 2,5

Postural balance is the ability to hold the body in a particular position against gravity after any destabilizing stimuli cease. With age, we start to lose dynamic and static balance control, which depends on our ability to maintain our center of gravity and to counteract the destabilizing external force. Furthermore, components of the posture control system degenerate, such as skin proprioceptors, muscles, joints, ligaments, organs of sight, the vestibular system, and the central and peripheral nervous systems. ${ }^{2,5,6}$

Risk factors for fall associated with pathological states include nervous system disorders (transient cerebral ischemia, post-cerebral stroke symptoms, Parkinson's disease, epilepsy), diseases of the sense organs (glaucoma, cataract, maculopathy, Ménière's disease, and labyrinthitis), musculoskeletal disorders (joint and spine degenerative diseases, inflammation of muscles and joints, deformation and diseases of feet, osteomalacia, osteoporosis), cardiovascular disease (arrhythmia, having recently suffered a heart attack, orthostatic hypotony), as well as digestive and urinary disorders (diarrhea, constipation, urinary incontinence, nocturia). Other conditions that predispose to falls include metabolic disorders such as hypoglycemia, anemia, water-electrolyte disturbances, malnutrition and dehydration, hypothyroidism, mental disorders (anxiety, depression, delirious states, and dementia), as well as feelings of pain and fatigue., ${ }^{2,5}$

One aim of the rehabilitation of elderly patients is to slow down involutional processes and, if possible, to improve physical and mental fitness. Regular health training for people over 60 years should improve basic elements of physical fitness: oxygen efficiency, muscle strength and power as well as suppleness, balance and motor coordination. The type, intensity, and frequency of activity should be tailored individually, depending on patients' current health status and physical fitness. The recommendations of the American College of Sports Medicine and of the American Heart Association suggest that regular physical activity should include elements of weight and endurance training, stretching, and balance exercises. ${ }^{7}$

From the point of view of rehabilitation, it is important that not only traditional approaches are employed (based on regular training, taking into account contraindications against physical exercise and having eliminated factors that increase potential risk), but that physiotherapeutic interventions are also undertaken to complement patients' main problems with everyday functioning. It has been demonstrated that function-oriented exercises minimize the risk of falls, on the whole improving balance, gait parameters, and the muscle strength of the lower limbs. ${ }^{8}$

Modern interactive forms of physical fitness based on virtual reality (VR) training are playing an increasingly important role in the rehabilitation of older individuals.

VR is an interactive computer-generated experience based on the visual representation of objects, spaces, and events. ${ }^{9}$ VR can also be described in terms of $\mathrm{I}^{3}$ : Interaction + Immersion + Imagination. ${ }^{10}$ VR can be presented in two ways: as a realistic world (a computer simulation) or as a fictional world (computer games). Computer technology is employed to create the effect of a 3-dimensional, interactive world where all objects, events, and feelings perceived through the senses seem real and present. ${ }^{9}$

VR rehabilitation can be implemented through personal computers (PCs), mobile devices, video game consoles, or specialist equipment dedicated to particular dysfunctions. The portability of a console, its relatively small size, and its endurance mean that each patient can have a small virtual rehabilitation room in his or her home. The Xbox Live service also enables remote control of such therapy. Another advantage of console-based rehabilitation is that reinforced biofeedback can be used to mobilize the nervous system to regenerate. ${ }^{11}$

\section{Aim of the study}

The aim of this study was to assess the effectiveness of VR training using the "Xbox 360 Kinect" in the context of reducing the risk of falls among elderly people.

\section{Materials and methods}

The study was conducted in accordance with the Declaration of Helsinki. The protocol of this study was approved by the Bioethical Commission of the Pomeranian Medical University in Szczecin (covered for blind review) (permission 
number KB-0012/45/16) and by the director of the daytime social welfare institution "Dom Kombatanta i Pioniera Ziemi Szczecińskiej".

\section{Material}

The study involved 23 residents of the daytime social welfare institution "Dom Kombatanta i Pioniera Ziemi Szczecińskiej" in Szczecin, Poland. Men made up $17.4 \%$ of the study sample (4 subjects), and women made up 82.6\% (19 subjects). The mean age was $75.74 \pm 8.09$ years. The respondents were also described in terms of their general health and concomitant diseases. The general characteristics of the study sample are shown in Table 1.

All participants gave their voluntary written informed consent for inclusion in the study and confirmed that they had been informed in detail about how the study was to be conducted, that they could quit the study at any moment without giving a reason and without suffering any negative

Table I General characteristics of the study sample

\begin{tabular}{|c|c|c|}
\hline \multirow[b]{2}{*}{ Sex } & \multicolumn{2}{|c|}{$\begin{array}{l}\text { Characteristics of the study } \\
\text { sample }(n=23)\end{array}$} \\
\hline & $n$ & $\%$ \\
\hline Women & 19 & 82.6 \\
\hline Men & 4 & 17.4 \\
\hline \multicolumn{3}{|l|}{ Age (years) } \\
\hline$<80$ & 14 & 60.9 \\
\hline$\geq 80$ & 9 & 39.1 \\
\hline \multicolumn{3}{|l|}{ Concomitant diseases } \\
\hline Hypertension & 18 & 78.26 \\
\hline Ischemic heart disease & 8 & 34.78 \\
\hline Diabetes & 8 & 34.78 \\
\hline Urinary disorders & 2 & 8.70 \\
\hline Digestive disorders & 10 & 43.48 \\
\hline Motor system diseases & 18 & 78.26 \\
\hline Neurological diseases & 4 & 17.39 \\
\hline Other diseases & 8 & 34.78 \\
\hline Other & Mean & \pm SD \\
\hline Age (years) & 75.74 & 8.09 \\
\hline Height $(\mathrm{cm})$ & 162.22 & 4.91 \\
\hline Weight (kg) & 68.91 & 9.07 \\
\hline Body mass index (BMI) & 21.25 & 2.80 \\
\hline $\mathrm{SBP}(\mathrm{mmHg})$ & 135.39 & 12.42 \\
\hline $\mathrm{DBP}(\mathrm{mmHg})$ & 80.91 & 10.32 \\
\hline Heart rate & 74.70 & 10.31 \\
\hline Number of diseases & 3.30 & 1.49 \\
\hline Number of drugs taken & 3.48 & 1.73 \\
\hline
\end{tabular}

Abbreviations: $n$, number of participants; SBP, systolic blood pressure; DBP, diastolic blood pressure consequences, and that they could ask questions and receive responses.

The participants were in a stable phase of any disease they suffered from and were qualified for the study by a physician and a physiotherapist.

\section{Methods}

Functional capacity was assessed using the "6-minute walking test (6MWT)", which allows assessment of the functioning of all the organs and systems involved in physical exercises (the respiratory system, the cardiovascular system, the systemic and peripheral circulation system, nervous and muscle structures, and muscle metabolism). The test is performed in a corridor at least $30 \mathrm{~m}$ long. The patient covers the route at his or her own pace, while a physiotherapist measures the time using a stopwatch and sums up the totals. The patient rests during the trial. Both before and after the test, the patient's blood pressure and pulse are measured. It is recommended that the patient rests in a sitting position for 10 minutes before the test and does not undertake any physical activity 2 hours prior to the test.

The potential risk of falls in the sample was evaluated using the "Dynamic Gait Index (DGI)", which consists of 8 trials that differ by the additional activities that are performed during the gait: walking a straight $20 \mathrm{~m}$ stretch at a changing pace while turning the head right and left, looking up and down, looking back, walking through obstacles, passing by obstacles, walking up and down the stairs. The patients who obtained scores of 18 or less were those at greatest risk of falling. Those who scored 19-21 were regarded as being at a moderate risk of falling, while those scoring 22-24 were classified as being at minimal risk of falling.

Static balance and the risk of falling in our advanced-age patients were assessed using the "tandem stance test (TST)". This can only be performed by patients who are able to adopt a heel-to-toe position. When trying to take the testing position, subjects may initially support themselves, ceasing the support when they hear a signal. The test involves patients maintaining a balanced heel-to-toe position for 10 seconds with a physiotherapist standing close by. The test ends after 10 seconds or when the patient uses his or her arm to gain support or takes a step. The results are interpreted as follows: maintaining the position for 10 seconds is taken as indicating normal balance, while maintaining the position for less than 3 seconds indicates a high risk of falls.

Balance and coordination during gait (dynamic balance) was evaluated using the "tandem walk test (TWT)", which estimates the risk of falls in elderly people. This test is not 
used on individuals with dementia, those needing another person's assistance, or those using orthopedic devices, such as crutches or walking frames. To perform the test, a $2 \mathrm{~m}$ long, $5 \mathrm{~cm}$ wide line is drawn on flat ground. The patient's task is to walk along the line in such a way that during each step, the heel of one foot touches the toes of another. The patient makes 10 such steps forward in that way, and this is repeated twice. The walking time and the number of mistakes are assessed, with only the best trial being considered. During the trial, the patient may not look at the feet or use balance reactions excessively. The patient is scored as follows: 5 , the patient is able to take seven steps without a break, placing the feet correctly and with good coordination; 4 , the patient is able to take more than three steps, placing the feet correctly, but with poor coordination; 3 , the patient is able to take more than three steps, placing the feet partially correctly; 2 , the patient is able to take two or three steps, but places the feet outside the line; 1 , the patient is able to take one step; 0 , the patient is unable to take even one step along the line (he or she requires assistance or takes sideways steps).

To assess depressive disorders, the "Beck Depression Inventory (BDI)" was employed. This is a 21-item self-rated scale. Each item is given a score from 0 to 3, depending on the severity of the symptoms. For each item, the patient chooses the one response that best reflects his or her state in the last 30 days. In this study, patients with total scores of 50-65 were regarded as having severe depressive episodes. Patients with scores of 27-49 and 12-26 points were, respectively, considered as having moderate and mild depressive episodes. Patients with lower scores (0-11) were considered as lacking depressive symptoms. The test results did not serve to give an unambiguous diagnosis of depression.

The following research materials were used in our study:

1. A "Microsoft Xbox 360 Sensor Kinect video game console" with a high-definition multimedia interface monitor. The sensor contains 2 cameras, an infrared (IR) light source, an accelerometer, an internal computer that controls an array of 4 microphones recording the sound that arrives from all directions, and a motor that allows the sensor's head to be drawn aside. The first camera is a Red-Green-Blue (RGB) camera used to process the visual image (eg, to recognize the parts of the body) and to mark colors and texture on the virtual elements. The second camera is a part of the sensor subsystem that gathers information about depth. The subsystem measures distance by means of structured light. An IR light source projects a cloud of points at certain distance from a recorder. The position of this cloud is recorded by the camera equipped with an infrared filter. This information about the distance from all points allows, for example, the person's posture to be recognized and his or her movements to be identified. The IR light source makes it possible to "transfer" the player's silhouette to the figure on the monitor.

2. A "spring hand dynamometer" for measuring the strength of the hand's pressing muscles (the grip strength). The measurement involves clenching the hand on the handle of the device as strongly as possible. The gauge indicators show the result in kilograms.

3. A "Geonaute ONrhythm 410 Pulsometer with a telemetry strap" enabled us to measure the patient's pulse. It was not necessary for the patients to wear the pulsometer on their wrists, because the range of the sensor on the strap is about $2 \mathrm{~m}$. Monitoring the patient's pulse enabled us to immediately interrupt the measurement if necessary.

4. A "Beurer's electronic manometer" for measuring pulse and blood pressure, which allowed the measurement of the diastolic and systolic blood pressure and pulse.

5. "Auxiliary materials" included colored tape $5 \mathrm{~cm}$ wide, measuring tape, and a stopwatch.

\section{Study design}

The research procedure consisted of 3 stages with different methodologies. Before entering the study, each patient was informed of its nature, course, and purpose.

In the first stage of the study, we employed the standardized research instruments: the 6MWT, the DGI, the TST, the TWT, and the BDI. We also measured the strength of the right and left hands using the spring hand dynamometer. Each patient had to meet the inclusion criteria in order to pass to the second stage.

All candidates were selected in strict accordance with the inclusion and exclusion criteria. The inclusion criteria were that the patient was sufficiently healthy to participate in the study; had sufficient intellectual capacity to notice, analyze, perceive, and adapt to changes in the environment, to properly interpret information and carry out the tasks in a logical manner; was over 60 years of age; completed the 6MWT, scored 19-24 on the DGI, scored over 10 seconds on the TST, and scored 27 points or less on the BDI. The exclusion criteria were that the patient lack sufficient health to participate in the study; had concomitant diseases that would be a threat to the patient's health or life during physical exercise (eg, unstable ischemic heart disease, being in the early phase after myocardial infarction, considerably hypertrophied heart 
muscle, symptoms of myocardial ischemia during low load exercises, arrhythmia, or conduction disorders occurring or becoming more severe even at low exercise load, tachycardia at rest, paroxysmal atrial fibrillation, multifocal R-on-T ventricular premature beats, heart defect, myocarditis or pericarditis, cardiomyopathy, decompensated circulatory insufficiency or coronary insufficiency at rest, pharmacologically uncontrolled hypertension, aortic aneurysm, acute aortic syndrome, venous thromboembolism, substantial limitation of pulmonary ventilation capacity, respiratory insufficiency, pulmonary embolism, acute mental disorders, neoplastic disease, uncompensated diabetes, weight exceeding $160 \%$ of normal, inflammation, epilepsy, or severe labyrinth disorders); failed to complete the 6MWT, scored below 19 points on the DGI, below 10 on the TST, or over 27 on the BDI.

The second stage of the study involved 30 days of VR training with the Xbox 360 Kinect. During training, each patient had their pulse monitored by means of a watch with a Geonaute ONrhythm 410 telemetry strap, and blood pressure was measured using an electronic manometer from Beurer prior to warm-up. In the same part of the project, the patients performed 12 exercises 3 times per week, each lasting 30 minutes.

The training consisted of the warm-up, football, bowling, and downhill skiing games in the Kinect Sports series for the Xbox 360 Kinect Sensor. Each player could choose from a dozen or so games, both full games (6) and shorter ones (12), which differed in terms of duration and number of repetitions. The subjects could also choose the number of players (from 1 to 4 ) and competitors (computer, friends, or people on the Internet).

Each game began when the patient confirmed his or her readiness to play by raising one hand over the head. One element that was helpful to the players was that comments were shown on the screen. No one was permitted to pass between the movement sensor and the player during play, as this would halt the match and require it to be restarted.

In the "football" game, the patients played the role of active team players. The active player was the one who had possession of the ball. Players were able to kick the ball; to take free, corner, and penalty kicks; to kick from the goal; to perform throw-ins; and to block opponents' shots. All these were performed through the movements of the lower and upper limbs and, where necessary, by leaning to the side. The purpose of the game was to score goals and ultimately to win the match. The lower limbs were the most active parts of the body.
One game that strongly activated the upper limbs was bowling, in which the player rolls a bowling ball down a lane toward 10 pins positioned at the end of it, the objective being to knock down as many pins as possible. Each game consisted of 10 frames, in each of which the bowler had 2 chances to knock down the pins. The ball could be thrown fast, slow, freely, with a twist, or in such a way that it damaged the bowling lane's surface, and all of these possibilities were regulated by the speed and rotation of the bowler's upper limb. The precision of a throw and the trajectory of the bowling ball were controlled by markers one-third of the way along the bowling lane. Depending on the player's actions, 1 of 7 markers was highlighted. The bowler could choose the arm used to bowl by shifting the arm through $90^{\circ}$. The winner was the one who knocked over the most pins in the least number of attempts.

The final game was downhill skiing. This involved the entire body, especially the torso and the spine-stabilizing muscles and the lower limbs, as the body was slightly bent in a squatting position. The upper limbs were less involved (pushing off with the ski poles at the start). The players' task was to ski as fast as possible without missing any of the 15 gates along the route. Turns were performed by bending the body to the left or the right, while lowering the shoulder on the same side. It was also possible to ski faster by bending forward (the maximum speed was described as 150 $\mathrm{km} / \mathrm{h}$ ). The player could choose 1 of the 3 routes and could select the experience level of the computer opponent. Once the finishing line had been crossed, the skiing time and the number of missed gates were shown on the screen. For each missed gate, the player was punished by having 2 seconds added to his or her time. The player with the shortest total time for 2 downhill runs was the winner.

The third stage of the study followed the same pattern as the first stage.

Statistical analysis was performed using a licensed copy of Statistica 12 (StatSoft, Tulsa, OK, USA). The results were generally shown as mean and standard deviation. The normality of the distribution was assessed using the ShapiroWilk test, and the quantitative data was assessed using the Mann-Whitney $U$-test. The differences before and after the training sessions were assessed using the Wilcoxon matchedpairs test for dependent variables. The level of significance was set at $P \leq 0.05$.

In the first part, we examined the relationship between the results of the tests before and after the training sessions. In the second part, the participants were divided into age groups: group 1 comprised individuals below 80 years and group 2 
included patients aged 80 years and older. We then investigated the relationships between the age groups and the test results before and after the training sessions.

\section{Results}

Analysis of the mean test results is shown in Table 2.

After the training sessions, the number of meters covered by participants in the 6MWT significantly increased $(P<0.001)$ and the probable risk of falls decreased $(P=0.008)$. Furthermore, there was a statistically significant improvement in static balance as assessed by the TST $(P<0.001)$ and in dynamic balance measured by the TWT $(P=0.002)$. There was also a significant decline in the tendency toward depressive disorders $(P<0.001)$. Only the strength of the pressing muscles in the right hand did not improve as a result of VR training.

The next analysis considered the age of the patients, who were divided into those aged below 80 years and those aged 80 years or more. In both these groups, the results of the 6MWT $(P<0.001$ and $P=0.008$, respectively) and the TST ( $P<0.001$ and $P=0.008$, respectively) considerably improved, and the tendency toward depressive disorders noticeably reduced ( $P=0.003$ and $P=0.012$, respectively). The TWT results $(P=0.012)$ were only better in the patients aged less than 80 years, while the DGI results $(P=0.043)$ only improved in the patients aged 80 years or more. VR training did not enhance the strength of the pressing muscles in either of the patients' hands. The data analysis is illustrated in Table 3.

There were no statistically significant relationships between the age of the participants and the results observed before and after the training sessions (Table 4).

All the participants stated that VR training was a way for them to halt the process of digital exclusion, and that it helped them adapt to training with modern technologies.

\section{Discussion}

In this study, we examined the effects of VR training using the Xbox 360 Kinect Sensor. We made use of tests for measuring balance and the risk of falls in elderly people, which can also be used to estimate general fitness. Dynamic stability was assessed by the DGI and the TWT, and static stability by the TST. The TST and the TWT were significant indicators of the elderly subject's functioning, especially in terms of their stability and fall prevention. Our study provided evidence that VR training can improve postural stability. Similar results have also been obtained by other researchers who evaluated the risk of falls during VR training by means of various tests, such as the Berg Balance Scale, ${ }^{12-16}$ the Activities-specific Balance Confidence Scale, ${ }^{13}$ the Fullerton Advanced Balance Scale, ${ }^{14}$ the Timed Up and Go test, ${ }^{14,16-19}$ and the Tinetti Test. ${ }^{15,18,20}$

In our study, the $6 \mathrm{MWT}$ revealed a considerable improvement in the patients' physical status. Parallel results based on the same test were reported by Deskur-Śmielecka et al. ${ }^{21}$ Karttunen et $\mathrm{al}^{22}$ reported that the walking distance and functioning improved during walking rehabilitation with the use of the 6MWT among elderly individuals after stroke. Perkowski et $\mathrm{al}^{23}$ indicated a positive correlation between the 6MWT and upper and lower limb strength test scores.

In the study presented here, there was a statistically significant improvement in dynamic balance as assessed by the TWT after the training sessions only among those aged below 80 years. Research results obtained by other authors showed that the TWT is not sensitive enough to detect older adults who are at risk of falls. ${ }^{24}$

Our findings demonstrated a statistically significant improvement in static balance as assessed by the TST after the training sessions both in the group of people below and over 80 years of age. Other studies reported that standing

Table 2 Test results before and after the training sessions

\begin{tabular}{|l|l|l|l|l|l|}
\hline \multirow{2}{*}{} & \multicolumn{2}{|l|}{ Before training (n=23) } & \multicolumn{2}{l|}{ After training (n=23) } & \multirow{2}{*}{-value } \\
\cline { 2 - 6 } & Mean & \pm SD & Mean & \pm SD & $<0.00$ I \\
\hline 6MWT & 173.70 & 64.76 & 215.43 & 65.75 & 0.008 \\
\hline DGI & 20.39 & 1.73 & 20.91 & 1.65 & $<0.001$ \\
\hline TST & 12.96 & 3.18 & 17.00 & 4.97 & 0.002 \\
\hline TWT & 3.70 & 0.70 & 4.26 & 0.62 & $<0.001$ \\
\hline BDI & 16.52 & 7.69 & 11.91 & 5.84 & 0.106 \\
\hline Dynamometer right hand & 13.09 & 5.76 & 12.74 & 5.45 & 0.043 \\
\hline Dynamometer left hand & 12.57 & 5.57 & 12.09 & 5.11 & \\
\hline
\end{tabular}

Abbreviations: 6MWT, 6-minute walking test; BDI, Beck Depression Inventory; DGI, Dynamic Gait Index; TST, tandem stance test; TWT, tandem walking test; n, number of participants. 
Table 3 Test results before and after the training sessions, by age

\begin{tabular}{|c|c|c|c|c|c|c|c|c|c|c|}
\hline & \multicolumn{5}{|c|}{ Age $<80$ years $(n=14)$} & \multicolumn{5}{|c|}{ Age $\geq 80$ years $(n=9)$} \\
\hline & \multicolumn{2}{|c|}{ Before training } & \multicolumn{2}{|c|}{$\begin{array}{l}\text { After training } \\
\text { sessions }\end{array}$} & \multirow[t]{2}{*}{$P$-value } & \multicolumn{2}{|c|}{ Before training } & \multicolumn{2}{|c|}{$\begin{array}{l}\text { After training } \\
\text { sessions }\end{array}$} & \multirow[t]{2}{*}{$P$-value } \\
\hline & Mean & \pm SD & Mean & \pm SD & & Mean & \pm SD & Mean & \pm SD & \\
\hline 6MWT & 188.57 & 71.67 & 227.86 & 77.38 & $<0.001$ & 150.56 & 46.87 & 196.11 & 38.31 & 0.008 \\
\hline DGI & 20.50 & 1.87 & 20.79 & 1.81 & 0.068 & 20.22 & 1.56 & 21.11 & 1.45 & 0.043 \\
\hline TST & 13.64 & 3.69 & 17.57 & 5.98 & $<0.001$ & 11.89 & 1.90 & 16.11 & 2.89 & 0.008 \\
\hline TWT & 3.86 & 0.66 & 4.43 & 0.51 & 0.012 & 3.44 & 0.73 & 4.00 & 0.71 & 0.068 \\
\hline $\mathrm{BDI}$ & 14.29 & 7.16 & 10.57 & 6.39 & 0.003 & 20.00 & 7.53 & 14.00 & 4.39 & 0.012 \\
\hline Dynamometer right hand & 13.86 & 6.81 & 13.36 & 6.45 & 0.109 & 11.89 & 3.62 & 11.78 & 3.49 & 0.655 \\
\hline Dynamometer left hand & 12.57 & 5.27 & 12.07 & 5.11 & 0.067 & 12.56 & 6.33 & 12.11 & 5.42 & 0.423 \\
\hline
\end{tabular}

Abbreviations: 6MWT, 6-minute walking test; BDI, Beck Depression Inventory; DGI, Dynamic Gait Index; TST, tandem stance test; TWT, tandem walking test; n, number of participants.

balance task performance evaluated by the TST was not related to age. ${ }^{25}$

In Poland, computer and console systems are possibly not as developed in terms of technology and marketing as in Japan, China, and the US. There has also been a lack of research in Poland concerning console games. Our study employed the Xbox 360 Kinect, the same tool as was used in the studies of Hsieh et al, ${ }^{26}$ Sin et al, ${ }^{27}$ and Lee. ${ }^{28}$ The literature also contains publications describing the use of the PlayStation $2,{ }^{29-31}$ the 3D Virtual Reality Kayak Program, ${ }^{32}$ and the VR-based Balance Rehabilitation Unit. ${ }^{33}$ The majority of researchers who examined the use of VR for balance rehabilitation in elderly people employed the Nintendo Wii system $^{32,35-37}$ with the Wii Balance Board module. ${ }^{16,38-40}$ Some other results worth mentioning are those obtained by authors who assessed general fitness in elderly patients after stroke incidents ${ }^{18,27,37}$ and those with Parkinson' ${ }^{36,41,42}$ or Alzheimer's disease ${ }^{43}$ with the use of functional tests and VR.
Our findings demonstrated that regularly playing console games had a significant effect on the patients' emotional sphere. We noticed a decrease in BDI scores, which should be interpreted as a lower proneness to depression. According to Kempen et al, ${ }^{44}$ a history of falls, limited functional capacity, the feeling of fear, and depressive symptoms observed in old people correlate with their avoidance of physical activity and fear of falling. There are also studies describing VR tools whose aim is to minimize the fear of falls $\mathrm{s}^{45}$ and chronic pain, ${ }^{46}$ and to improve the quality of sleep in elderly disabled people. ${ }^{47}$ Based on their analysis of research into the reduction of depressive symptoms by means of VR, Zeng et $\mathrm{al}^{48}$ described that, in most cases, VR had a positive impact on the physical and mental state of the participants. Only one study did not confirm the superiority of VR training over traditional exercises.

Taking the above mentioned findings into account, we should mention other benefits that arose from our elderly

Table 4 Differences between the mean results before and after the training sessions, by age

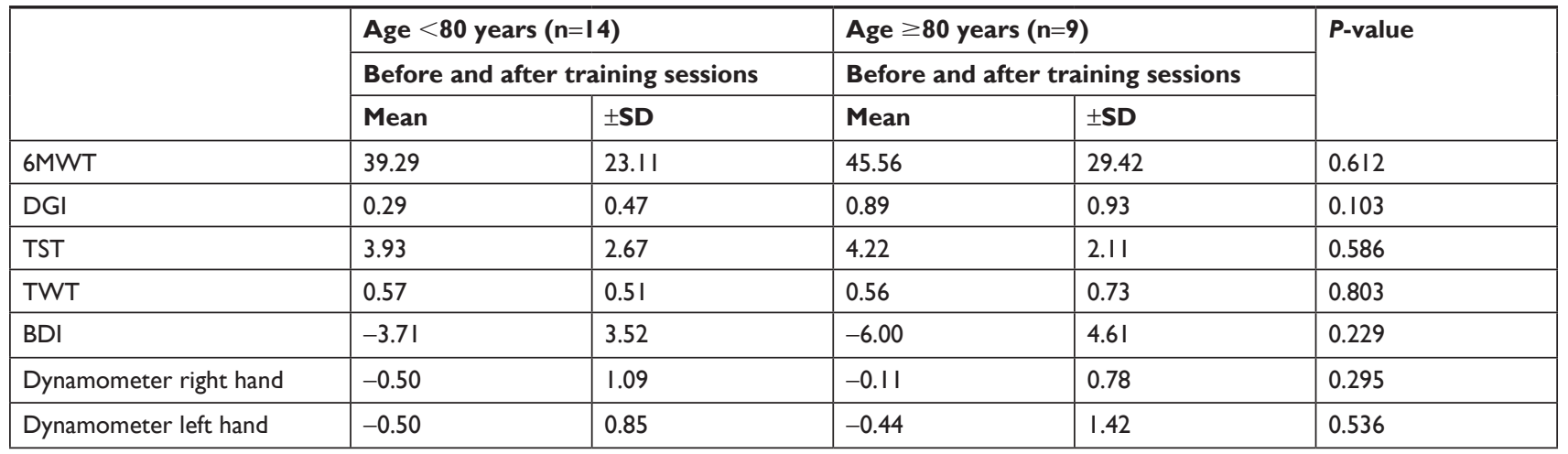

Abbreviations: 6MWT, 6-minute walking test; BDI, Beck Depression Inventory; DGI, Dynamic Gait Index; TST, tandem stance test; TWT, tandem walking test; $n$, number of participants. 
subjects' use of console games. All the participants in our study regarded VR training as a good way to prevent digital exclusion. As indicated by Flynn et $\mathrm{al}^{30}$ and Rand et al, ${ }^{31}$ VR training is perceived by elderly people as something fun that motivates them to undertake activity. Moreover, the technologies discussed here are safe and affordable and can be successfully used by elderly people in their home environment. ${ }^{49}$

The limitation of the present study is the fact that we did not evaluate the patients' cognitive status using a standardized scale in reference to the inclusion criteria. The only prerequisite was the patient's ability to understand and follow verbal instructions and carry out the tasks in a logical manner. It would be worth evaluating whether a mild cognitive decline is related to exercise capacity.

Another limitation is that the participants in our study were not divided into study and control groups, and no comparative analysis was performed. Research of this type has been conducted by Bieryla and Dold, ${ }^{14}$ Franco et al, ${ }^{15}$ Maillot et al, ${ }^{50}$ and Rendon et al. ${ }^{34}$ Nonetheless, despite numerous reports showing that therapy with console games is a more or less effective way of restoring functional capacity in elderly people, some investigators still retain doubts about it. On the basis of her literature review concerning the use of Nintendo Wii, Taylor ${ }^{51}$ deduced that there have been too few randomized studies of elderly people so far to unambiguously state that it is a tool suitable for balance exercises.

Van Diest et al, ${ }^{52}$ who went through publications about video game console technologies and their impact on elderly people's ability to maintain balance, has made a similar point. These authors believe that it is impossible to say which technologies have the best influence on patients. Kiper et al, ${ }^{53}$ on the other hand, maintain that training based on modern computer technologies, video, and robots has positive effects, especially in the case of people with neurological disorders, those who have had strokes, and those with disturbed function of the upper and lower limbs. These authors emphasize the innovative character of the studies of these issues and believe that the difficulties associated with collecting study samples may result from potential participants' health conditions, reluctance, and fear of new technologies. In their meta-analysis of the effectiveness of a VR intervention in improving balance in adults, Booth et $\mathrm{al}^{54}$ have pointed to the substantial inconsistencies of the results of experimental and control studies. Molina et al ${ }^{55}$ assert that VR research should be continued and conducted on even larger study samples, in order to obtain higher methodological quality and thus provide stronger scientific evidence, because the effect of using console games on the physical functioning of elderly people remains unclear. Some researchers agree that training with reinforced feedback in a virtual environment helps to maintain functional capacity and may be an element of comprehensive physiotherapeutic intervention; however, they do not believe that it has been unambiguously established that VR can serve as an alternative to conventional kinesiotherapy.

\section{Conclusion}

VR training increases the possibilities of motor training and can help reduce the risk of falls by improving the static and dynamic balance.

The conclusions of our research are limited by the size of the study sample. In further research on this topic, it would be sensible to examine the effectiveness of the training method in individuals with and without a history of falls.

\section{Disclosure}

The authors report no conflicts of interest in this work.

\section{References}

1. World Population Ageing 1950-2050. New York: United Nations Department of Economic and Social Affairs, Population Division; 2002. Available from: http://www.un.org/esa/population/publications/ worldageing19502050/. Accessed July 10, 2018.

2. WHO global report on falls prevention in older age. Geneva. World Health Organization 2008. Available from: http://www.who.int/iris/ handle/10665/43811. Accessed July 10, 2018.

3. WHO. Falls. Fact Sheet. Available from: http://www.who.int/mediacentre/factsheets/fs344/en/. Accessed July 10, 2018.

4. National Council on Aging. Falls Prevention Facts. Available from: https:/www.ncoa.org/news/resources-for-reporters/get-the-facts/fallsprevention-facts/. Accessed July 10, 2018.

5. Guccione AA, Wong RA, Avers D. Geriatric Physical Therapy. St. Louis: Elsevier Mosby; 2012.

6. Lord SR, Sherrington C, Menz HB. Falls in Older People: Risk Factors and Strategies for Prevention. Cambridge: Cambridge University Press; 2002.

7. Nelson ME, Rejeski WJ, Blair SN, et al; American College of Sports Medicine; American Heart Association. Physical activity and public health in older adults: recommendation from the American College of Sports Medicine and the American Heart Association. Circulation. 2007;116(9):1094-1105.

8. Żak M, Swine C, Grodzicki T. Combined effects of functionallyoriented exercise regimens and nutritional supplementation on both the institutionalised and free-living frail elderly (double-blind, randomised clinical trial). BMC Public Health. 2009;9:39.

9. Demos NJ. Getting Started with Neurofeedback. New York: W.W. Norton \& Company; 2005.

10. Burdea GC. Virtual rehabilitation - benefits and challenges. Methods Inf Med. 2003;42(5):519-523.

11. Kiper P, Turrola A, Piron L. Virtual reality for stroke rehabilitation: assessment, training and the effect of virtual therapy. Medical Rehabilitation. 2010;14(2):15-23.

12. Williams B, Doherty NL, Bender A, Mattox H, Tibbs JR. The effect of nintendo wii on balance: a pilot study supporting the use of the wii in occupational therapy for the well elderly. Occup Ther Health Care. 2011;25(2-3):131-139. 
13. Bainbridge E, Bevans S, Keeley B, Oriel K. The effects of the Nintendo Wii Fit on community-dwelling older adults with perceived balance deficits: A pilot study. Phys Occup Ther Geriatr. 2011;29(2): 126-135.

14. Bieryla KA, Dold NM. Feasibility of Wii Fit training to improve clinical measures of balance in older adults. Clin Interv Aging. 2013; 8:775-781.

15. Franco JR, Jacobs K, Inzerillo C, Kluzik J. The effect of the Nintendo Wii Fit and exercise in improving balance and quality of life in community dwelling elders. Technol Health Care. 2012;20(2):95-115.

16. In T, Lee K, Song C. Virtual reality reflection therapy improves balance and gait in patients with chronic stroke: Randomized Controlled Trials. Med Sci Monit. 2016;22:4046-4053.

17. Laver K, George S, Ratcliffe J, et al. Use of an interactive video gaming program compared with conventional physiotherapy for hospitalised older adults: a feasibility trial. Disabil Rehabil. 2012;34(21): 1802-1808.

18. Pluchino A, Lee SY, Asfour S, Roos BA, Signorile JF. Pilot study comparing changes in postural control after training using a video game balance board program and 2 standard activity-based balance intervention programs. Arch Phys Med Rehabil. 2012;93(7):1138-1146.

19. Schoene D, Lord SR, Delbaere K, Severino C, Davies TA, Smith ST. A randomized controlled pilot study of home-based step training in older people using videogame technology. PLoS One. 2013;8(3):e57734.

20. Toulotte C, Toursel C, Olivier N. Wii Fit ${ }^{\mathbb{R}}$ training vs. Adapted Physical Activities: which one is the most appropriate to improve the balance of independent senior subjects? A randomized controlled study. Clin Rehabil. 2012;26(9):827-835.

21. Deskur-Śmielecka E, Jóźwiak A, Bosacka M. Wpływ krótkotrwałego programu rehabilitacyjnego o małej intensywności na wydolność fizyczną u pacjentów w podeszłym wieku [Effects of short-term, lowintensity rehabilitation program on physical capacity in the elderly]. Gerontol Pol. 2011;19(1):21-28. Polish

22. Karttunen AH, Kallinen M, Peurala SH, Häkkinen A. Walking training and functioning among elderly persons with stroke: results of a prospective cohort study. PM R. 2015;7(12):1205-1214.

23. Perkowski R, Gajos M, Kujawski S, Kujawska A, Jarecka J, Dobosiewicz AM. Correlation of the 6-minute walk test with BMI an lower and upper limb strenght tests results in older people. Preliminary studies. Gerontol Pol. 2015;25:151-155.

24. Chantanachai T, Pichaiyongwongdee S, Jalayondeja C. Fall prediction in Thai elderly with timed up and go and tandem walk test: a crosssectional study. J Med Assoc Thai. 2014;97(Suppl 7):S21-S25.

25. Hile ES, Brach JS, Perera S, Wert DM, Vanswearingen JM, Studenski SA. Interpreting the need for initial support to perform tandem stance tests of balance. Phys Ther. 2012;92(10):1316-1328.

26. Hsieh WM, Chen CC, Wang SC, et al. Virtual reality system based on Kinect for the elderly in fall prevention. Technol Health Care. 2014; 22(1):27-36.

27. Sin H, Lee G. Additional virtual reality training using Xbox Kinect in stroke survivors with hemiplegia. Am J Phys Med Rehabil. 2013;92(10): $871-880$

28. Lee G. Effects of training using video games on the muscle strength, muscle tone, and activities of daily living of chronic stroke patients. $J$ Phys Ther Sci. 2013;25(5):595-597.

29. Lee S, Shin S. Effectiveness of virtual reality using video gaming technology in elderly adults with diabetes mellitus. Diabetes Technol Ther. 2013;15(6):489-496.

30. Flynn S, Palma P, Bender A. Feasibility of using the Sony PlayStation 2 gaming platform for an individual poststroke: a case report. J Neurol Phys Ther. 2007;31(4):180-189.

31. Rand D, Kizony R, Weiss PT. The Sony PlayStation II EyeToy: lowcost virtual reality for use in rehabilitation. J Neurol Phys Ther. 2008; 32(4):155-163.

32. Park J, Yim J. A New Approach to Improve Cognition, Muscle Strength, and Postural Balance in Community-Dwelling Elderly with a 3-D Virtual Reality Kayak Program. Tohoku J Exp Med. 2016;238(1):1-8.
33. Duque G, Boersma D, Loza-Diaz G, et al. Effects of balance training using a virtual-reality system in older fallers. Clin Interv Aging. 2013; 8:257-263.

34. Rendon AA, Lohman EB, Thorpe D, Johnson EG, Medina E, Bradley B. The effect of virtual reality gaming on dynamic balance in older adults. Age Ageing. 2012;41(4):549-552.

35. Cho GH, Hwangbo G, Shin HS. The effects of virtual reality-based balance training on balance of the elderly. J Phys Ther Sci. 2014;26(4): 615-617.

36. Liao YY, Yang YR, Cheng SJ, Wu YR, Fuh JL, Wang RY. Virtual Reality-Based Training to Improve Obstacle-Crossing Performance and Dynamic Balance in Patients With Parkinson's Disease. Neurorehabil Neural Repair. 2015;29(7):658-667.

37. Saposnik G, Cohen LG, Mamdani M, et al; Stroke Outcomes Research Canada. Efficacy and safety of non-immersive virtual reality exercising in stroke rehabilitation (EVREST): a randomised, multicentre, singleblind, controlled trial. Lancet Neurol. 2016;15(10):1019-1027.

38. Clark RA, Bryant AL, Pua Y, McCrory P, Bennell K, Hunt M. Validity and reliability of the Nintendo Wii Balance Board for assessment of standing balance. Gait Posture. 2010;31(3):307-310.

39. Young W, Ferguson S, Brault S, Craig C. Assessing and training standing balance in older adults: a novel approach using the "Nintendo Wii" Balance Board. Gait Posture. 2011;33(2):303-305.

40. Koslucher F, Wade MG, Nelson B, Lim K, Chen FC, Stoffregen TA. Nintendo Wii Balance Board is sensitive to effects of visual tasks on standing sway in healthy elderly adults. Gait Posture. 2012;36(3): 605-608.

41. Arias P, Robles-García V, Sanmartín G, Flores J, Cudeiro J. Virtual reality as a tool for evaluation of repetitive rhythmic movements in the elderly and Parkinson's disease patients. PLoS One. 2012;7(1): e30021.

42. Killane I, Fearon C, Newman L, et al. Dual motor-cognitive virtual reality training impacts dual-task performance in freezing of gait IEEE J Biomed Health Inform. 2015;19(6):1855-1861.

43. García-Betances RI, Jiménez-Mixco V, Arredondo MT, CabreraUmpiérrez MF. Using virtual reality for cognitive training of the elderly. Am J Alzheimers Dis Other Demen. 2015;30(1):49-54.

44. Kempen GI, van Haastregt JC, McKee KJ, Delbaere K, Zijlstra GA. Socio-demographic, health-related and psychosocial correlates of fear of falling and avoidance of activity in community-living older persons who avoid activity due to fear of falling. BMC Public Health. 2009;9:170.

45. Levy F, Leboucher P, Rautureau G, Komano O, Millet B, Jouvent R. Fear of falling: efficacy of virtual reality associated with serious games in elderly people. Neuropsychiatr Dis Treat. 2016;12:877-881.

46. Jones T, Moore T, Choo J. The impact of virtual reality on chronic pain. PLoS One. 2016;11(12):e0167523.

47. Chang LC, Wang CY, Yu P. Virtual reality improves sleep quality amongst older adults with disabilities. Int J Geriatr Psychiatry. 2014; 29(12):1312-1313.

48. Zeng N, Pope Z, Lee JE, Gao Z. Virtual reality exercise for anxiety and depression: a preliminary review of current research in an emerging field. J Clin Med. 2018;7(3):E42.

49. Prosperini L, Fortuna D, Giannì C, Leonardi L, Marchetti MR, Pozzilli C. Home-based balance training using the Wii balance board: a randomized, crossover pilot study in multiple sclerosis. Neurorehabil Neural Repair. 2013;27(6):516-525.

50. Maillot P, Perrot A, Hartley A. Effects of interactive physical-activity video-game training on physical and cognitive function in older adults. Psychol Aging. 2012;27(3):589-600.

51. Taylor D. Can Wii improve balance? New Zeland J Physioter. 2011; 39(3):131-133.

52. van Diest M, Lamoth CJ, Stegenga J, Verkerke GJ, Postema K. Exergaming for balance training of elderly: state of the art and future developments. J Neuroeng Rehabil. 2013;10:101.

53. Kiper P, Szczudlik A, Mirek E. The application of virtual reality in neuro-rehabilitation: motor re-learning supported by innovative technologies. Medical Rehabilitation. 2013;17(4):29-36. 
54. Booth V, Masud T, Connell L, Bath-Hextall F. The effectiveness of virtual reality interventions in improving balance in adults with impaired balance compared with standard or no treatment: a systematic review and meta-analysis. Clin Rehabil. 2014;28(5):419-431.
55. Molina KI, Ricci NA, de Moraes SA, Perracini MR. Virtual reality using games for improving physical functioning in older adults: a systematic review. J Neuroeng Rehabil. 2014;11:156.

\section{Publish your work in this journal}

Clinical Interventions in Aging is an international, peer-reviewed journal focusing on evidence-based reports on the value or lack thereof of treatments intended to prevent or delay the onset of maladaptive correlates of aging in human beings. This journal is indexed on PubMed Central, MedLine,
CAS, Scopus and the Elsevier Bibliographic databases. The manuscript management system is completely online and includes a very quick and fair peer-review system, which is all easy to use. Visit http://www.dovepress. com/testimonials.php to read real quotes from published authors. 